\title{
Single-Sided Ultrasonic Welding of CF/Nylon 6 Composite without Energy Directors
}

\author{
An analytical model to explain the weldability of single-sided \\ ultrasonic welded 2.5-mm-thick carbon-fiber-reinforced \\ nylon 6 compositewith $30 \%$ mass fiber was formulated
}

BY L.-Y. CHEN, Q. ZHI, J.-C. LI, Z.-X. LIU, AND P.-C. WANG

\begin{abstract}
In this study, single-sided ultrasonic welding along with conventional ultrasonic welding of 2.5-mm-thick carbon-fiber-reinforced nylon 6 composite with $30 \%$ mass fiber without energy directors was evaluated. An analytical model to estimate the heat generation in single-sided ultrasonic welding was developed. Testing and modeling results demonstrated that single-sided ultrasonic welded (SSUW) joints had greater weld area and strength than conventional ultrasonic welds (UWs) under the given process parameters. The differences in weld area and weld strength were primarily attributed to severe Coulomb friction at the faying surfaces. The bending deformation in single-sided ultrasonic welding generated significant friction heat, resulting in an increase in weld area and weld strength. This study provided a fundamental understanding of single-sided ultrasonic welding that would improve the design flexibility of ultrasonic welded assemblies.
\end{abstract}

\section{KEYWORDS}

- Carbon-Fiber-Reinforced Nylon 6 Composite $\bullet$ Weld Formation • Weldability

- Single-Sided Ultrasonic Welding • Transient Horn Displacement

\section{Introduction}

In recent years, with the development of manufacturing and processing technologies, fiber-reinforced (e.g., glass or carbon fiber) nylon matrix composites have been extensively applied to high technology fields such as aviation/aerospace and automotive industries (Refs. 1-5). A critical step in the assembly of fiber-reinforced thermoplastic composite for structural applications is joining. Traditional joining methods for metals and thermosets, such as mechanical fastening (Ref. 6) and adhesive bonding (Ref. 7), are feasible but not ideal because they can initiate several irregularities in the structures. For example, mechanical fastening may cause fiber breakage (Ref. 6), stress concentration (Ref. 8), delamination (Ref. 9), internal stress caused by different thermal expansion of the fasteners relative to the composites (Ref. 10), and possible galvanic corrosion (Ref. 11). Adhesive bonding often requires surface pretreatment and heat curing (Refs. 7, 11); the strength of the bonded joints are sensitive to the moisture (Ref. 7), temperature, and other environmental factors (Ref. 12). Other than mechanical fastening and adhesive bonding, a few studies in fusion methods (Refs. 10, 13-15) demonstrated their potential for joining fiber-reinforced thermoplastic composites. Among all these potential methods, ultrasonic welding is one of the most promising techniques in automotive manufacturing because it is relatively fast, economical, easily automated, and suitable for mass production (Refs. 13, 16-20).

Ultrasonic welding is a process where workpieces are placed between a horn and anvil. Mechanical vibration passes between the horn and anvil through the workpieces under a given horn force. Heat is generated within the workpieces by intermolecular friction at the joint interface, and energy dissipation is concentrated at the faying surfaces between the workpieces, forming a weld (Refs. 18-20). The key control parameters in ultrasonic welding are the frequency, amplitude of the vibratory motion, horn pressure, and welding time (Ref. 21).

Although many joint configurations were used in the ultrasonic welding of thermoplastics (Refs. 22-24), the lap joint is the most widely used for automotive applications (Ref. 22). In the practical production, the welding of the workpieces may be constrained by part geometry and designs. Singlesided ultrasonic welding is needed in such conditions where it is difficult to access the backside of the lower workpieces in conventional ultrasonic welding. Therefore, the difference between single-sided ultrasonic welding and conventional ultrasonic welding is that there is no anvil underneath the lower workpiece - Fig. 1.

In the single-sided ultrasonic welding process, ultrasonic vibration is conducted through the horn, and the vibration wave is transmitted through the upper and lower workpieces to the clamp. Whether the absence of an anvil would affect weld formation is a major concern. To implement singlesided ultrasonic welding, it is necessary that the development and understanding of the single-sided ultrasonic welding process be obtained.

The present study was undertaken to 


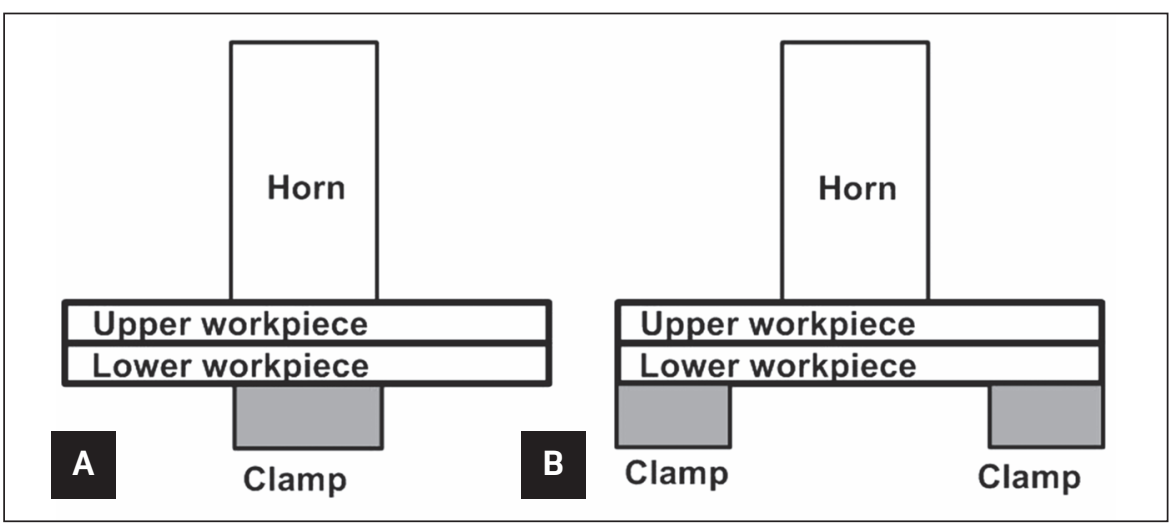

Fig. 1 - Schematics of ultrasonic welding: A - Conventional; B - single-sided ultrasonic welding.

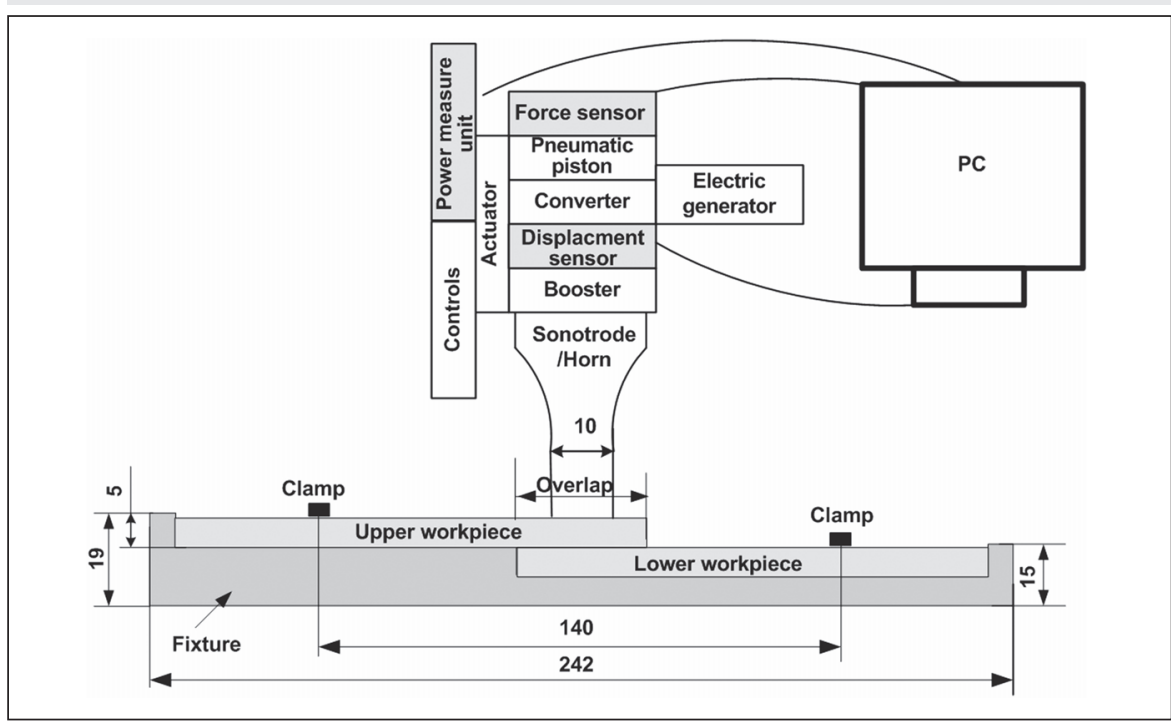

Fig. 2 - Schematic of ultrasonic welding of injection-molded carbon-fiber-reinforced nylon 6 composite (dimensions in $\mathrm{mm}$ ).

develop a single-sided ultrasonic welding process for joining lapped carbonfiber-reinforced nylon 6 composite with $30 \%$ mass fiber. First, we evaluated the effect of suspension distance on the weldability of single-sided ultrasonic welding of 2.5-mm- (0.08-in.-) thick carbon-fiber-reinforced nylon 6 composite with $30 \%$ mass fiber without energy directors. Then, the correlation between the weld formation and transient horn displacement was analyzed, and the influence of process parameters on the transient horn displacement was assessed. Finally, an analytical model was proposed and formulated to explain the weld formation mechanism in singlesided ultrasonic welding.

\section{Experimental Procedure}

\section{Materials}

Commercial pellets of nylon 6 reinforced with 30 wt-\% carbon-fiber com-

Table 1 - Mechanical Properties of Molded 2.5-mm- (0.099-in.-) Thick Carbon-FiberReinforced Nylon 6 Composite Coupons with 30\% Mass Carbon Fiber

Tensile Strength

(MPa)

$\left(\mathrm{lb} /\right.$ in. $\left.\left.^{2}\right)\right)$

$89.2 \pm 3$
Elastic Modulus

$\begin{array}{cc}\text { (MPa) } & \left.\text { (lb/in. }^{2}\right) \\ 7532 \pm 412 & (1.1 \pm 0.6) \times 10^{6}\end{array}$

posite with a length of $2 \mathrm{~mm}$ were supplied by Poliblend Engineering Plastics, Italy. The pellets were injection-molded and formed carbon-fiberreinforced nylon 6 composite with the dimensions of $132 \times 38 \times 2.5 \mathrm{~mm}(5.2$ $\times 1.5 \times 0.08$ in.). The mechanical properties of the injection-molded workpieces were measured and the results are shown in Table 1.

\section{Ultrasonic Welding Process}

The ultrasonic welding process was performed using a KZH-2026 multifunction ultrasonic weld (UW) machine (Ref. 25) with a nominal power of $2.6 \mathrm{~kW}$ and a nominal frequency of $20 \mathrm{kHz}$. The output amplitude of the transducer used in this study was 25 $\mu \mathrm{m}\left(9.8 \times 10^{-4}\right.$ in. $)$, which was fixed during the welding process. The gain ratios of the booster and horn were $1: 1.2$ and $1: 1.5$, respectively. The displacement amplitude of the assembled stack was obtained with a sensor that was integrated in the welding machine. Figure 2 shows the welding setup used in this study.

The piezoelectric converter converts the electrical signal into mechanical vibrations. To transfer the ultrasonic waves to the workpiece, the transducer is connected to the horn that is placed at right angles in contact with the workpieces to be welded. The support frame of the transducer-booster-horn system is attached to a pneumatic piston that provides vertical movement along with the static force (i.e., horn pressure) applied through the horn to the workpieces. The machine was also equipped with a data acquisition system combined with a pressure sensor; a horndisplacement sensor and timer were integrated in the controller of the UW machine, while the horn pressure, weld energy, and displacement of horn were recorded online in a personal computer as a function of time by the data acquisition system. The final horn displacement, weld energy, welding time, horn pressure, hold time, and delay time were also displayed in the control panel during the ultrasonic welding process. The workpieces were clamped with a fixture as shown in Fig. 2.

The machine includes three welding modes: energy, time, and horndisplacement modes. The value of the weld energy for energy mode, the 
welding time for time mode, and the horn displacement for horn-displacement mode were preset to control the welding process. The workpieces were then welded using nominal power of the machine. To keep the stable contact among the horn, upper, and lower workpieces at the beginning of ultrasonic oscillation, the ultrasonic wave generator was triggered after the horn was in contact with the upper workpiece for $2 \mathrm{~s}$ (i.e., a trigger time of $2 \mathrm{~s}$ ). When the weld energy, welding time, or horn displacement reached the preset values for the selected weld mode, the ultrasonic wave oscillation was stopped. Therefore, the weld quality was controlled by the preset values in each selected welding mode.

\section{Single-Sided Ultrasonic Welding}

Figure 3 shows a single-sided ultrasonic welding process. As shown, the workpiece was placed against another workpiece, with the lower workpiece resting upon a fixture. The horn was then placed against the upper workpiece. Ultrasonic vibration was conducted to the horn, and the vibration waves were transmitted through the upper and lower workpieces to the backup fixture that underlined the lower workpiece. A weld was formed at the faying interface between the workpieces.

To simulate the single-sided ultrasonic welding process, shims were used to create a gap of $2 \mathrm{~mm}$ between the bottom surface of the lower workpiece and fixture. A lap-shear joint with the dimensions of $25 \times 38 \mathrm{~mm}$ $(0.99 \times 1.5$ in. $)$ shown in Fig. $3 \mathrm{~A}$ was selected in this study. By spacing the distance between the shims, various degrees of single-sided ultrasonic welding were achieved - Fig. 3B. Noted in Figs. 2 and 3, the difference between single-sided ultrasonic welding and conventional ultrasonic welding was that the lower workpiece was supported with one fixed fixture for conventional ultrasonic welding $(0 \mathrm{~mm}$ suspension distance), while the workpieces were supported with two clamps on both ends of the overlap in single-sided ultrasonic welding. Ultrasonic welding was performed using the $\mathrm{KZH}-2026$ multifunction ultrasonic welding machine (Ref. 25) with nominal power and the preset process pa-
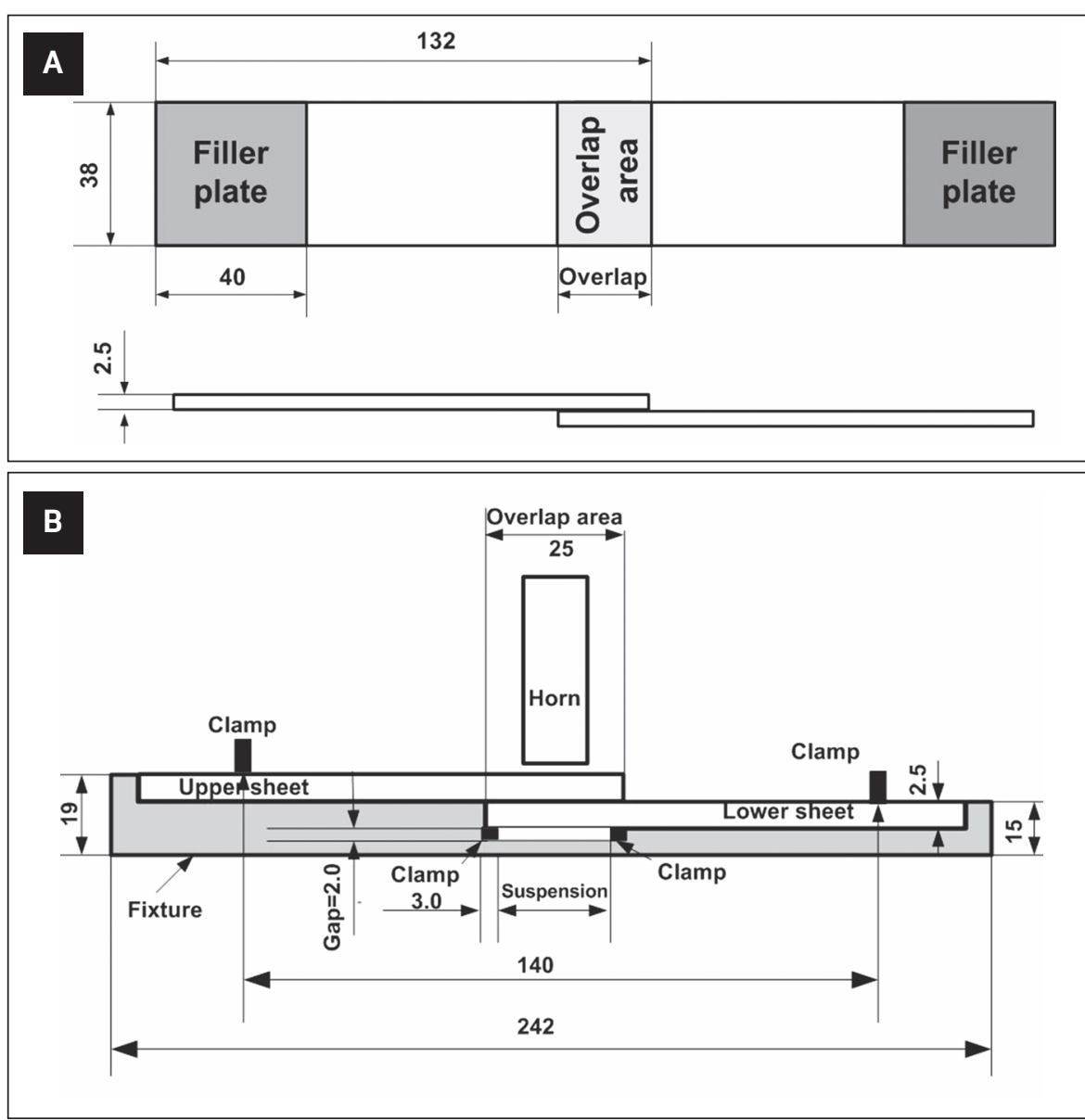

Fig. 3 - Schematics of: A - Lap-shear specimen; B - single-sided ultrasonic welding (dimensions in $\mathrm{mm}$ ).

rameters (i.e., ultrasonic time, horn pressure, and hold time). When the weld time approached the preset value, the ultrasonic wave oscillation was stopped and the welded joints were cooled for $5 \mathrm{~s}$. All joints were welded with a horn pressure of $0.3 \mathrm{MPa}$ (43.52 lb/in. ${ }^{2}$ ) and a welding time of 1.3 s using a 7075 aluminum horn with a diameter of $10 \mathrm{~mm}$. The weld area and weld strength were used as an indicator of weld quality. The weld area and weld strength were determined by the average value of three replicates for each welding condition.

\section{Transient Temperature Measurement}

To analyze weld initiation and growth during ultrasonic welding, the temperature evolutions at the locations near the horn-workpiece interface and faying surfaces were measured. Figure 4 shows the experimental setup for temperature measurements. As shown, two small holes with a diameter of $0.8 \mathrm{~mm}$ (0.032 in.) and a depth of $12.5 \mathrm{~mm}$ (0.49 in.), located at $0.2 \mathrm{~mm}$ (0.008 in.) from the top and bottom surfaces of the upper workpiece, were drilled. Two K-type thermocouples were imbedded in two small holes and secured with epoxy compound. The temperature evolutions at these two locations were recorded as a function of time by a data acquisition system during ultrasonic welding.

\section{Quasi-Static Test}

Quasi-static tests were performed by loading each specimen to failure in an MTS 810 tensile tester per ASTM D1002-2001 for the joint strength of the weld joint. To minimize the bending stresses inherent in the testing of single-lap weld specimens, filler plates shown in Fig. 3A were attached to both 


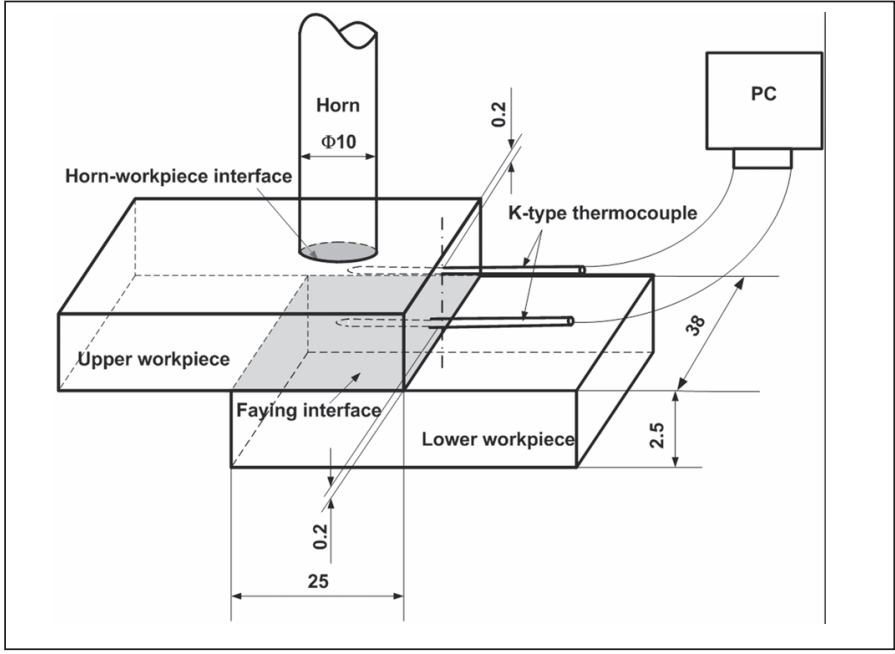

Fig. 4-Schematics of the temperature measurements during ultrasonic welding of 2.5-mm- (0.099-in.-) thick lapped carbonfiber-reinforced nylon 6 composite without energy directors (dimensions in $\mathrm{mm}$ ).

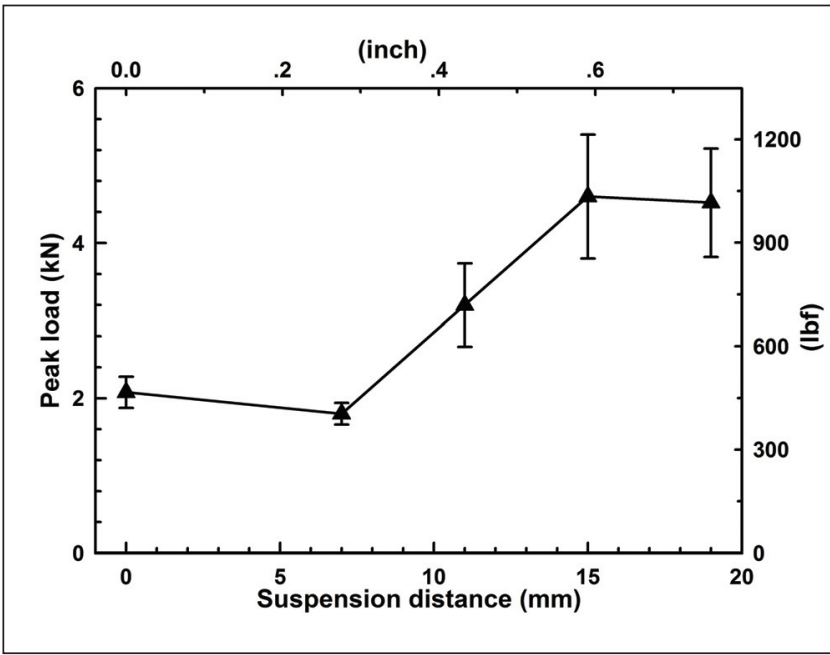

Fig. 5 - Effect of suspension distance on the strength of ultrasonic welded 2.5-mm- (0.099-in.-) thick carbon-fiberreinforced nylon 6 composite without energy directors.

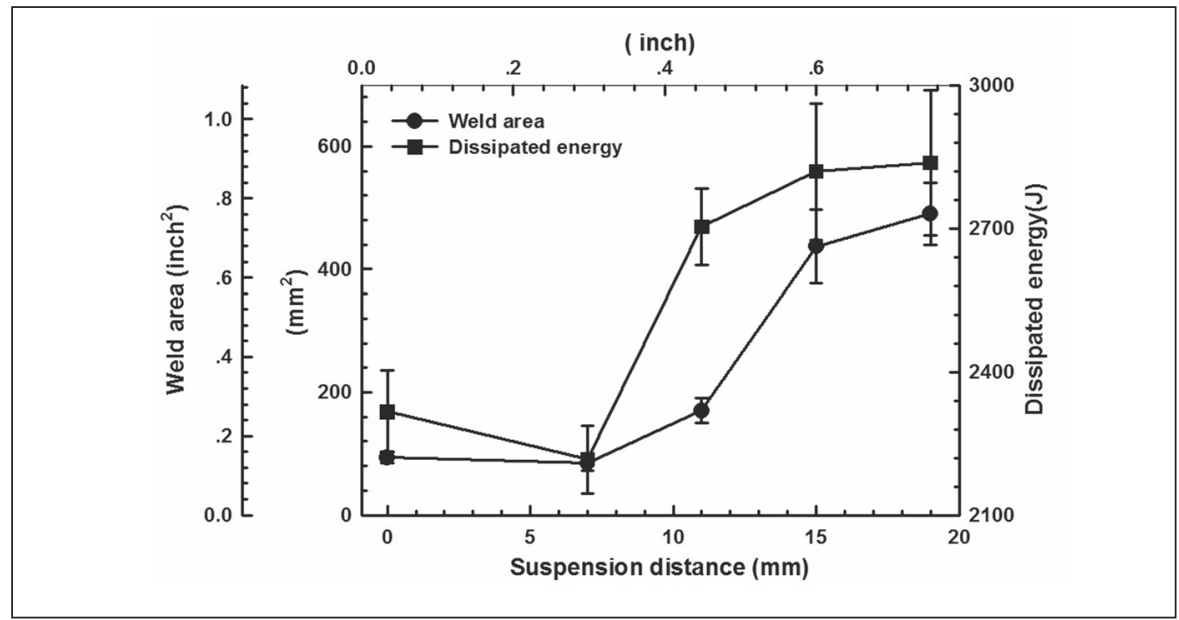

Fig. 6-Effect of suspension distance on the weld area and dissipated energy in ultrasonic welding of 2.5-mm- (0.099-in.-) thick carbon-fiber-reinforced nylon 6 composite without energy directors.

ends of the specimen using masking tape to accommodate the sample offset. Load vs. displacement results were acquired as the specimens were loaded at a stroke rate of $2 \mathrm{~mm} / \mathrm{min}(0.08 \mathrm{in} . /$ min). The joint strength was evaluated by the peak load. Three replicates were performed, and the average peak loads were reported.

\section{Results and Discussion}

\section{Weldability of Single-Sided Ultrasonic Welding}

For single-sided ultrasonic welding, the workpieces were clamped on both ends, and there was no anvil on the underside of the lower workpiece Fig. 3B. One concern was that ultrasonic waves would not properly transmit and reflect, and form a weld during ultrasonic welding.

To examine the weldability of single-sided ultrasonic welding of 2.5mm- (0.099-in.-) thick carbon-fiber reinforced nylon 6 composite with $30 \%$ mass fiber without energy directors, experiments were performed with various suspension distances, referred to in Fig. 3B. Figure 5 presents the effect of suspension distance on the strength of single-sided ultrasonic welded joints. While the strength of single-sided ultrasonic welded (SSUW) joints changed little as the suspension distance increased from 0 (i.e., conventional ultrasonic welding) to $7 \mathrm{~mm}$ (0.276 in.) and 15 (0.591) to $19 \mathrm{~mm}$ (0.749 in.), it increased significantly as the suspension distance increased from 7 (0.276) to $15 \mathrm{~mm}$ (0.591 in.).

To understand why the strengths of the SSUW joints were hardly degraded by the absence of an anvil, the weld areas of the SSUW workpieces were measured and heat dissipation of the weld controller was recorded. Figure 6 presents the effect of suspension distance on the weld area and heat dissipation in ultrasonic welding. As shown, an increase in suspension distance resulted in an increase in weld area that was closely related to the dissipated energy absorbed by the welded workpieces. Similar results were observed by Bates et al. (Refs. 26, 27). Combining the results shown in Figs. 5 and 6 indicated that an increase in dissipated energy during ultrasonic welding resulted in an increase in weld area. These results inferred that weld formation in single-sided ultrasonic welding likely differed from that of conventional ultrasonic welding.

To understand the increase in weld area and dissipated energy in singlesided ultrasonic welding, the transient temperature histories near the hornworkpiece interface and faying surfaces were measured with the setup shown in Fig. 4, and the results are shown in Fig. 7. As shown, it took about $0.8 \mathrm{~s}$ for conventional ultrasonic 


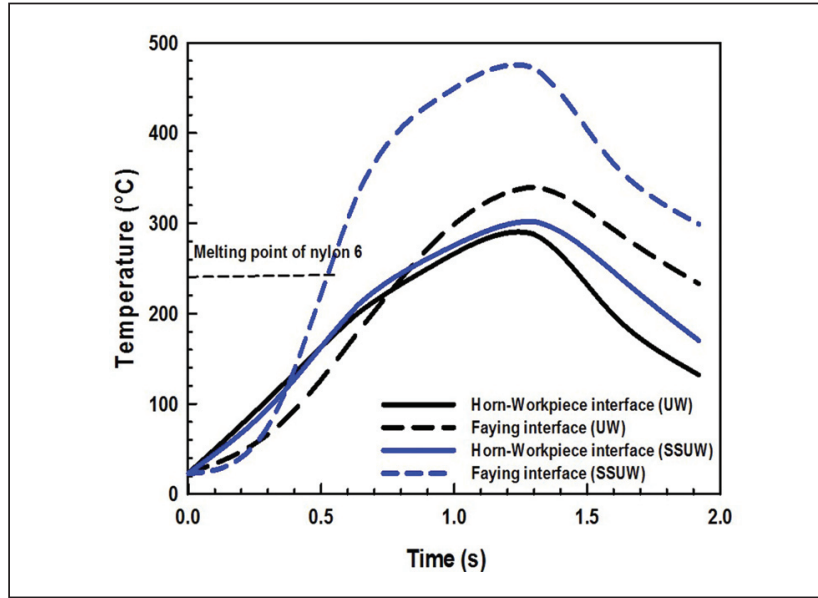

Fig. 7 - Transient temperature-time histories of the near horn-workpiece interface and faying surface of ultrasonic welding ( $\mathrm{mm}$ suspension distance) and single-sided ultrasonic welding (19 $\mathrm{mm}$ (0.749 in.) suspension distance) of 2.5-mm- (0.099-in.-) thick carbon-fiber-reinforced nylon 6 composite.

welding and $0.5 \mathrm{~s}$ for single-sided ultrasonic welding to reach the melting point of nylon 6 (i.e., $240^{\circ} \mathrm{C} / 464^{\circ} \mathrm{F}$ ) near the faying surfaces, respectively. The higher peak temperature and heating rate observed in single-sided ultrasonic welding suggested that more dissipated energy was absorbed by the SSUW joints (Refs. 28, 29), which was consistent with the results found in Fig. 6.

\section{Transient Horn Displacement in Ultrasonic Welding}

In Fig. 7, the suspension distance influenced the temperature evolutions that may correlate with weld initiation and growth. To understand how the suspension distance would influence the weld growth mechanism in ultrasonic welding, the transient horn displacements were measured with the data acquisition system connected to the UW machine, and the results are presented in Fig. 8. As shown, the horn moved downwards under a given horn pressure during ultrasonic welding as the result of heat generation at the faying surfaces, which softened and melted the workpieces. Therefore, the weld growth evolutions were likely reflected by the variations of transient horn movement. Careful examination of the results shown in Fig. 8 indicated that the transient horn displacement during ultrasonic welding could be divided into four phases (Refs. 30, 31).

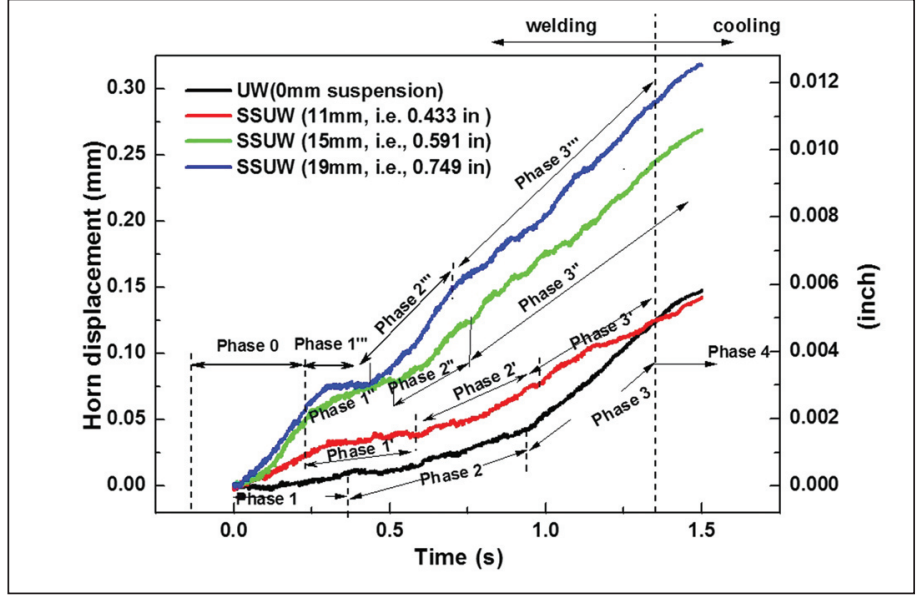

Fig. 8 - Effect of suspension distance on the horn displacement in ultrasonic welding of 2.5-mm- (0.099-in.-) thick carbon-fiberreinforced nylon 6 composite.

Phase I was the solid Coulomb friction stage ranging from 0 to $\sim 0.3 \mathrm{~s}$; Phase II was the unsteady penetration stage ranging from 0.3 to $0.8 \mathrm{~s}$; Phase III was the steady penetration stage ranging from 0.8 to $1.3 \mathrm{~s}$; and Phase IV was the cooling stage starting from $1.3 \mathrm{~s}$. In addition to these four phases, at the beginning of the single-sided ultrasonic welding process, there was an initial horn displacement, identified as Phase 0 (0 to $0.3 \mathrm{~s}$ ), which increased with an increase in suspension distance. Compared to the conventional ultrasonic welding process, as the suspension distances were above $11 \mathrm{~mm}$ (0.433 in.) in single-sided ultrasonic welding, the rate of increase in the penetrate phase increased significantly. These results suggested that the weld not only initiated early but also grew rapidly in single-sided ultrasonic welding, which were consistent with the findings observed in Fig. 7.

\section{Weld Formation in Ultrasonic Welding}

As the results described, the weld initiated early and grew rapidly as the suspension distance increased in single-sided ultrasonic welding. Because there was no anvil underneath the lower workpiece, the workpieces were under bending under an applied horn pressure during single-sided ultrasonic welding. This affected the contacts at the faying surfaces of the workpieces, and thus influenced the weld formation (Ref. 29).
To understand how the suspension distance affected the weld formation, the fracture surfaces of the quasi-static tested ultrasonic welded specimens were examined.

Figure 9A-E show the weld areas for the welds made with the suspension distances of $0,7,11,15$, and 19 $\mathrm{mm}(0,0.276,0.433,0.591$, and 0.749 in.), respectively. As shown, while a single weld was fabricated in conventional ultrasonic welding, multiple isolated welds were formed for a suspension distance of $7 \mathrm{~mm}$ (0.276 in.), referring to Fig. 9A and B. These results demonstrated that the welds made with a suspension distance of $7 \mathrm{~mm}$ (0.276 in. < a 10-mm (0.394-in.) diameter horn) had a similar welding mechanism to that of conventional ultrasonic welding. Because the upper and lower workpieces were constrained under the horn or near the clamps, the resistance to vibrations rose for the workpieces adjacent to the clamps.

The ultrasonic waves likely transmitted through the clamp-to-workpiece interface and led to the welded workpieces vibrating, and consequently produced the major welds along the clamps. As the suspension distance increased to $11 \mathrm{~mm}$ (0.433 in.), quite different findings were observed in Fig. 9C. While the minor welds formed along the clamps, the major welds were formed at the faying surfaces underneath the periphery of the horn-toworkpiece interface. These results suggested that there likely existed another welding mechanism other than the conventional ultrasonic welding mech- 

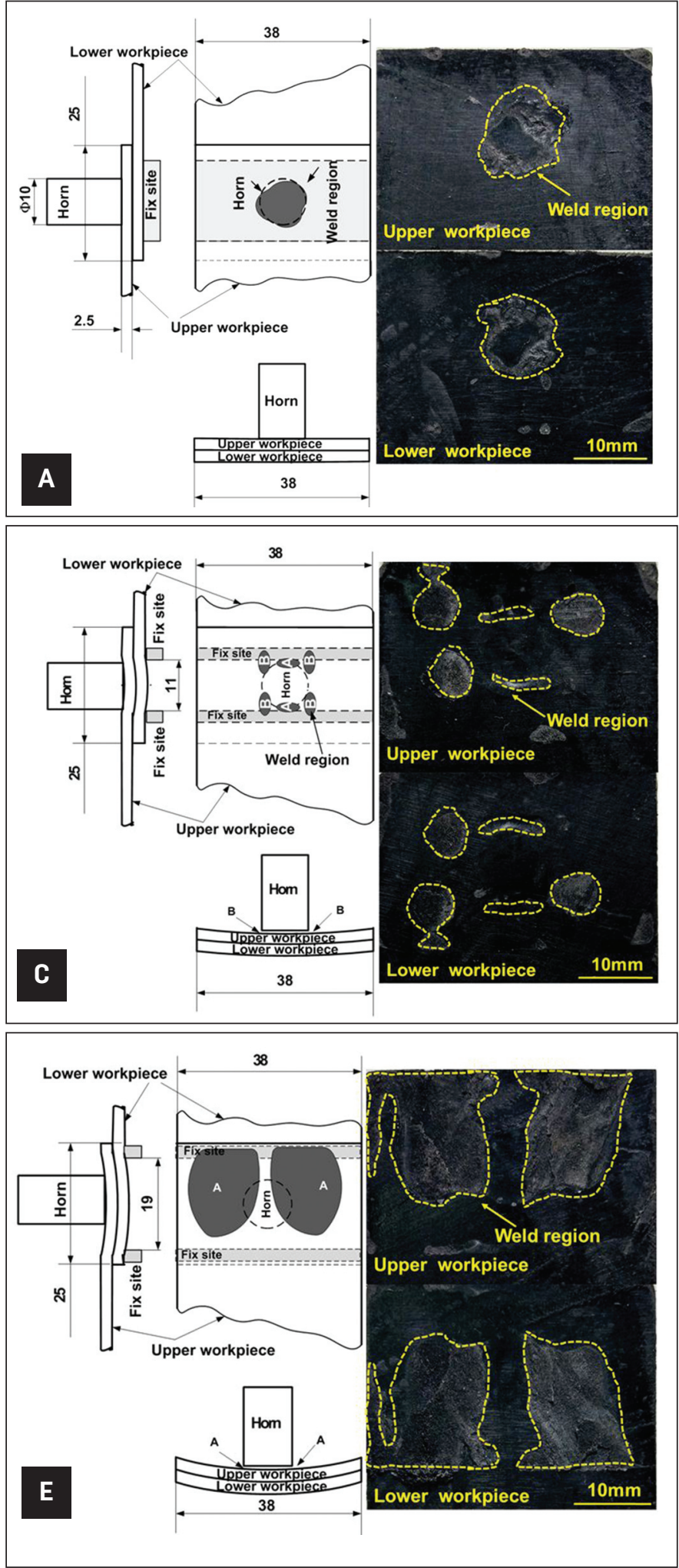
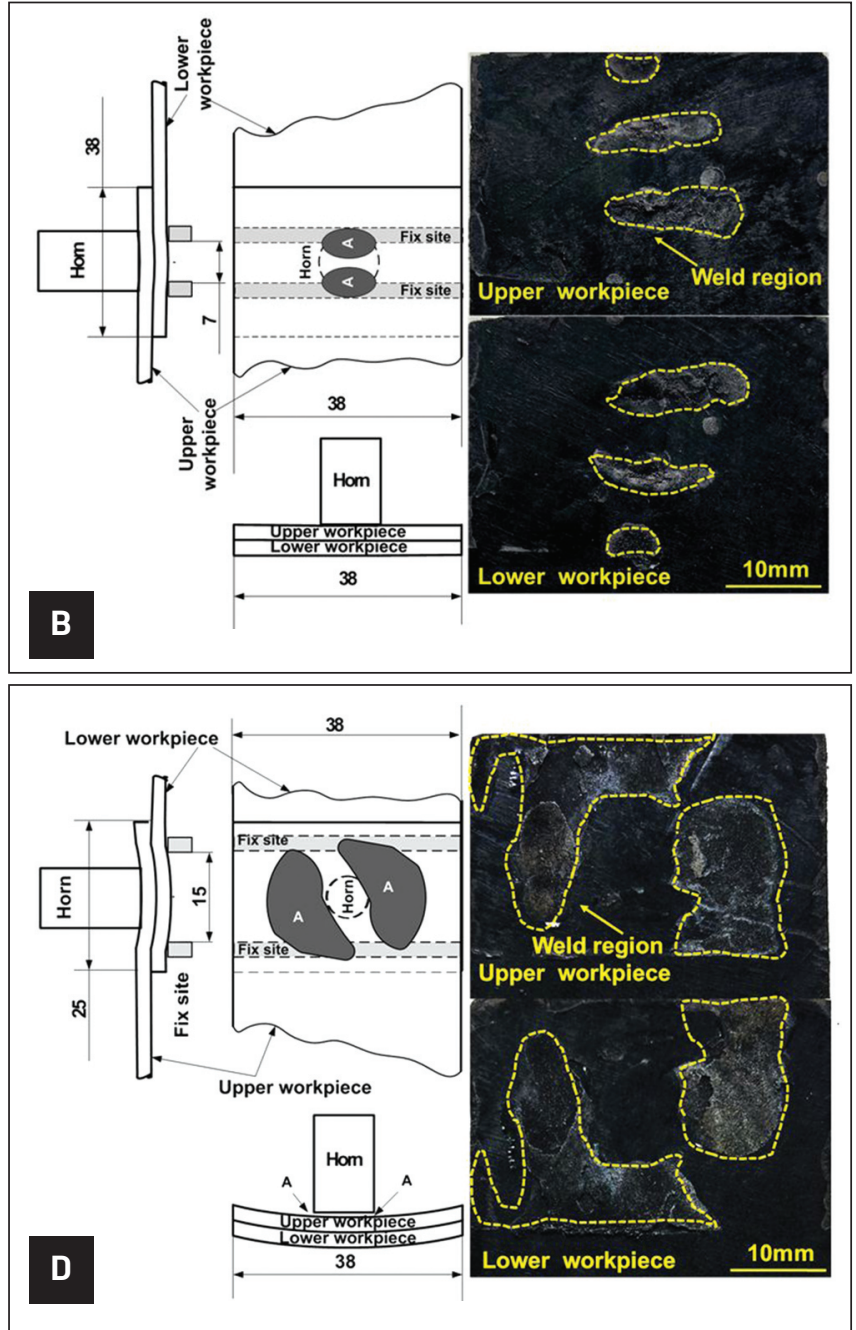

Fig. 9-Effect of suspension distance on the fracture surfaces of ultrasonic welded 2.5-mm- (0.099-in.-) thick lap carbon-fiber-reinforced nylon 6 composite: $A-0 \mathrm{~mm}$ (i.e., ultrasonic welding); $B-7 \mathrm{~mm}(0.276 \mathrm{in.}) ; C-11 \mathrm{~mm}(0.433$ in.); $D-15 \mathrm{~mm}$ (0.591 in.); and $E-19 \mathrm{~mm}$ (0.749 in.) (dimensions in $\mathrm{mm}$ ).

width direction than in the length direction (i.e., longer axis of the workpiece), and the bending deformation caused an additional relative movement on the faying surfaces along the tangent direction anism. Referring to Fig. 9C, the workpieces began to bend downward under a given horn pressure when the suspension distance of $11 \mathrm{~mm}$ (0.433 in.) was slightly larger than the horn diameter (i.e., $10 \mathrm{~mm}(0.394 \mathrm{in}$.)). The workpieces deformed easier in the of the deformed workpieces during ultrasonic oscillations.

The heat generated due to Coulomb friction resulting from relative movement of the workpieces could be combined with the heat produced due to intermolecular friction to melt the mate- rials at the faying surfaces. It is noted that the bending deformation in the width direction resulted in an asymmetrical contact at the faying surfaces (labeled as B in Fig. 9C), which likely led to an intimate contact (at site B) between the workpieces. As discussed earlier, the constrained site between the upper and lower workpieces had large resistance to vibrations, and the power dissipated in ultrasonic welding was related to the pressure at the contact regions (Refs. $21,30,31)$. Hence, the heat was generated and formed the weld pools at site B. Meanwhile, two minor welds (labeled A in Fig. 9C) were resulted from the heat produced due to intermolecular friction at the faying surfaces near two clamps. 

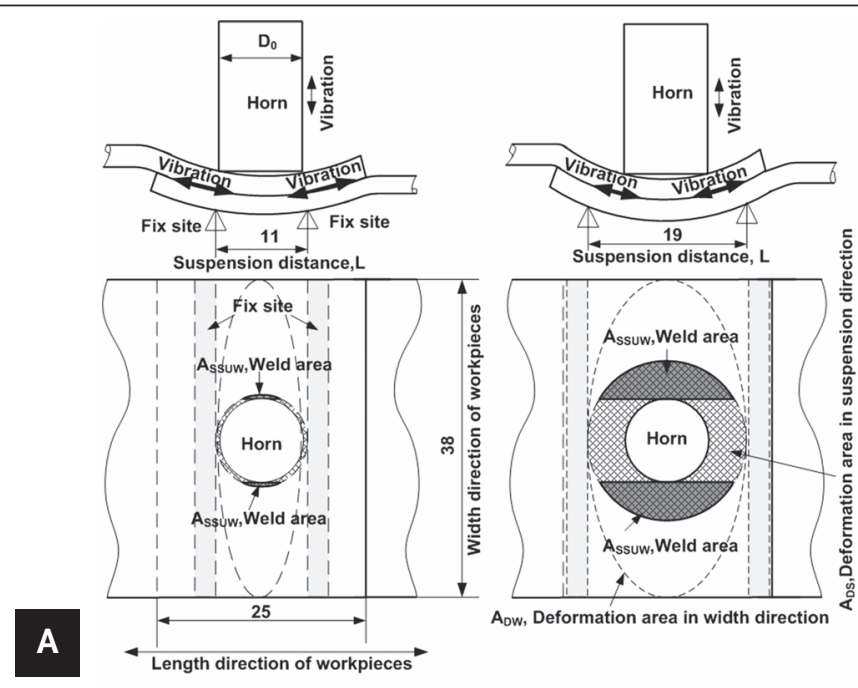

B

Fig. 10 - Schematics on the effect of suspension distance on the weld formation in ultrasonic welding of 2.5-mm- (0.099-in.-) thick carbon-fiber composite: A - $11 \mathrm{~mm}$ (0.433 in.); $B-19 \mathrm{~mm}$ (0.749 in.) (dimensions in $\mathrm{mm}$ ).

With an increase in suspension distance from 11 (0.433) to $15 \mathrm{~mm}(0.591$ in.) and $19 \mathrm{~mm}$ (0.749 in.), more bending deformation was produced under a given horn pressure, and consequently the contact areas between the horn and upper workpiece gradually evolved to form a weld - Fig. 9D and E. The weld initiated at the faying surfaces near the periphery the of horn-to-workpiece interface (i.e., labeled A in Fig. 9D and E) and grew toward the clamps rather than forming near the clamps. These results suggested that the heat due to Coulomb friction was produced at the faying surfaces as the suspension distance increased. Furthermore, Coulomb friction was more severe in the width direction than in the suspension direction due to their difference in bending deformation, which resulted in more friction heat in the width direction. Additionally, the weld formed at the intersection of the clamps and the periphery of the horn-to-workpiece interface as shown in Fig. 9D and E. These results inferred that the change of suspension distance affected the contacts between the hornto-workpiece and workpiece-to-workpiece, and consequently the heat generation at the faying surfaces.

\section{Modeling of Single-Sided Ultrasonic Welding}

As the results described, the workpieces deformed during squeeze cycle prior to ultrasonic oscillations, and the deformed workpieces sprung back once the horn was retrieved. It was assumed that a relative motion developed at the faying surfaces along both width and length directions. The tangential and normal motions between the workpieces led to Coulomb friction and intermolecular friction, respectively, which resulted in heat generation at the faying surfaces during ultrasonic welding. To understand the heat generation, an analytical model shown in Fig. 10 was derived. For simplification, the workpieces between two clamps were assumed deformed independently in directions of coupon width and length. The deformed regions in width and suspension directions of the workpieces were represented as $A_{D W}$ and $A_{D S}$, respectively Fig. 10B. A ring-like superimposed deformed region (plaid region in Fig. 10) was formed between the horn and clamps, in which the materials were under severe deformation and had a relative tangent movement at the faying surfaces during ultrasonic welding.

Referring to Figs. 9 and 10, as the suspension distances increased from 11 to $19 \mathrm{~mm}$ (0.433 to $0.749 \mathrm{in}$.), the workpieces had more compliance in width direction than in the length direction and consequently deformed easier in the width direction than in the suspension direction. The normal motion and tangential motion at superimposed regions $A_{\text {SSUW }}$ (dark plaid region $A B C A$ in Fig. 10B) generated

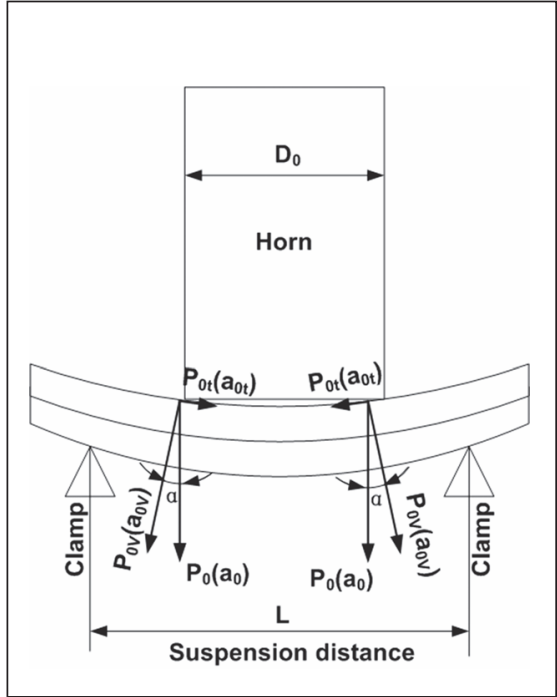

Fig. 11 - Sketch of force and amplitude analysis during squeeze cycle in single-sided ultrasonic welding.

heat due to intermolecular friction and Coulomb friction of the workpieces, which melted the workpieces at the faying surfaces. The weld area, $A_{\text {ssuw }}$, can be estimated from the area difference between the sectoral region $\mathrm{OABC}$ and triangular region $\mathrm{OAC}$ in Fig. 10B as follows:

$$
\begin{aligned}
& A_{\text {ssuw }}=\frac{L^{2}}{4} \times \operatorname{arc}\left(\cos \left(\frac{D_{0}}{L}\right)\right) \\
& -\frac{D_{0}}{4} \sqrt{L^{2}-D_{0}^{2}}
\end{aligned}
$$

where $L$ is the suspension distance and $D_{0}$ is the horn diameter. By substituting the horn diameter (i.e., $10 \mathrm{~mm}$ (0.394 in.)) and suspension distances (i.e., 11 (0.433), 15 (0.591), and 19 $\mathrm{mm}(0.749$ in.)) into Equation 1, it clearly shows that an increase in suspension distance resulted in an increase in weld area $\left(A_{\text {ssuw }}\right)$, which agreed with the experimental results observed in Fig. 9C-E.

Once the weld formation in singlesided ultrasonic welding was analyzed, the next question was how the heat generation at the faying surfaces was influenced by the changes in suspension distance. Careful examination of the experimental setup indicated that the changes in suspension distance would result in complex horn pressure distribution on the workpieces, and a finite element analysis would be desirable to understand the correlation between the suspension distance and 
heat generation. However, due to the lack of the coefficients of friction between the objects (e.g., the workpieces-to-clamps), a simplified analysis was adopted in this study.

Examination of the results in Fig. 9C and $\mathrm{D}$ indicated that the weld formation near the periphery of the horn-toworkpiece interface (i.e., regions A) likely came from the heat due to Coulomb friction resulting from the bending deformation of the workpieces under a horn pressure. Since Coulomb friction heat in single-sided ultrasonic welding of polymeric composite is likely similar to that of ultrasonic welding of metallic workpieces, the heat generation model (Refs. 32-34) for metallic workpieces was adopted in this study.

Per the model of Elangovan (Ref. 32), Ding (Ref. 33), and De Vries (Ref. 34 ), the heat generated, $W_{\text {metal }}$, in ultrasonic welding of metallic material was primarily from the deformation of workpieces and friction at the faying surfaces of the workpieces, which can be expressed as follows (Ref. 34):

$$
\begin{aligned}
& W_{\text {metal }}=4 a_{0} f \\
& \left(A_{w} \times \sqrt{=\left(\left(P_{0} / A_{w}\right) / 2\right)^{2}}+\mu P_{0}\right)
\end{aligned}
$$

where $a_{0}$ is the horn amplitude; $f$ is the horn frequency; $P_{0}$ is the horn pressure; and $\sigma_{s}, \mu$, and $A_{w}$ are the yield strength, coefficient of static friction, and weld area of metallic material, respectively.

Referring to $10 \mathrm{~B}$, Coulomb friction in this study was from the tangent movement of the workpieces at the faying surfaces during ultrasonic oscillation, and the resultant heat formed a weld in the dark plaid region ABCA. Because the workpieces had a fixed width $(38 \mathrm{~mm})$, the horn pressure and amplitude in single-sided ultrasonic welding can be estimated using the four-point bending beam shown in Fig. 11. As shown, the vertical component $\left(P_{0 n}\right)$ of the horn pressure $P_{0}$, and the normal $\left(a_{0 n}\right)$ component and tangential component $\left(a_{0 t}\right)$ of the horn amplitude $\left(a_{0}\right)$ can be expressed, respectively, as follows:

$$
\begin{aligned}
& P_{0 n}=P_{0} \cos \alpha \\
& a_{0 t}=a_{0} \sin \alpha \\
& a_{0 n}=a_{0} \cos \alpha
\end{aligned}
$$

where $\alpha$ is the angle of rotation of the workpiece under an applied horn pressure in single-sided ultrasonic welding, which can be estimated per classical mechanics of material:

$$
\alpha=\frac{P_{0} L\left(L^{2}-D_{0}^{2}\right)}{16 E l}
$$

where $L$ is the suspension distance, $D_{0}$ is the horn diameter, and $E l$ is the rigidity of the welded workpieces. Replaced $P_{0}$ and $a_{0}$ in Equation 2 with $P_{0 n}$ in Equation 3 and $a_{0 t}$ in Equation 4, respectively, the power dissipated, $W_{\text {coulomb }}$, in the sectoral region $\mathrm{ABCA}$ of the SSUW workpieces (Fig. 10B) to generate Coulomb frictional heat can be expressed as follows:

$$
\begin{aligned}
& W_{\text {coulomb }}=4 f a_{0} \sin \alpha \times A_{\text {ssuw }} \\
& \times \sqrt{\left(\sigma_{s} / 2\right)^{2}=\left(\left(P_{0} \cos \alpha / A_{\text {ssuw }}\right) / 2\right)^{2}} \\
& (\text { deformation power }) \\
& +\frac{1}{2} \mu P_{0} \sin 2 \alpha \\
& \text { (friction power) }
\end{aligned}
$$

Because the heat generated due to intermolecular friction from the normal motion of the workpieces was like that of conventional ultrasonic welding of polymer, the power dissipated to produce intermolecular friction, $W_{\text {intermolecular }}$ is related to the frequency of ultrasonic oscillation, normal amplitude $\left(a_{0 n}\right)$ of the horn, and loss modulus of the carbon-fiber nylon composite shown below (Ref. 30):

$$
W_{\text {intermolecular }}=2 \pi f a_{0}^{2} E^{\prime \prime} \cos \alpha
$$

where $E$ " is the loss modulus of the carbon-fiber composite. The combination of Equations 1, 6, 7, and 8 revealed that an increase in suspension distance resulted in an increase in angle of rotation of the workpiece $(\alpha)$ and $A_{\text {ssuw. }}$. Therefore, as the power dissipated for generation of the Coulomb friction heat increased (i.e., Equation 7), the power dissipated for producing the intermolecular friction heat decreased (i.e., Equation 8). The total power dissipated, $W_{\text {SSUW }}$, in singlesided ultrasonic welding of workpieces can be obtained as

$$
W_{\text {SSUW }}=W_{\text {intermolecular }}+W_{\text {coulomb }}
$$

The results in Fig. 6 indicated that an increase in suspension distance re- sulted in an increase in dissipated power $\left(W_{\text {SSUW }}\right)$ in SSUW workpieces. However, based on Equations 7-9, an increase in suspension distance resulted in an increase in $W_{\text {coulomb }}$ (Equation 8) but a decrease in $W_{\text {intermolecular }}$ (Equation 7). Thus, the increase in $W_{\text {SSUW }}$ likely resulted from the increase in $W_{\text {coulomb }}$ that overrode the decrease in $W_{\text {intermolecular }}$ as the suspension distance increased, which led to additional heat at the faying surfaces.

\section{Summary}

In this study, the weldability of single-sided ultrasonic welding of 2.5mm- (0.099-in.-) thick carbon-fiberreinforced nylon 6 composite with $30 \%$ mass fiber without energy directors was studied. Modeling and experimental results demonstrated that the single-sided ultrasonic welded (SSUW) joints possessed greater heat generation, weld area, and weld strength than conventional ultrasonic welded joints for the given process variables. The use of this process can increase the design and manufacturing flexibility of ultrasonic welded assemblies. However, the single-sided ultrasonic welding process developed in this study had some notable limitations in practical application. The bending deformation of the workpieces in single-sided ultrasonic welding induced coulomb friction that would likely produce warpage and residual stresses in the welded workpieces. The warpage and residual stresses may result in dimensional issues and weakened mechanical strengths of the welded workpieces. Therefore, more studies, such as part assembly and fatigue strength of the SSUW workpieces, are required before the implementation of the process for practical application.

\section{Conclusions}

1) For the given process variables, the SSUW 2.5-mm- (0.099-in.-) thick carbon-fiber-reinforced nylon 6 composite had greater heat generation, weld area, and weld strength than the conventional ultrasonic welded joints.

2) The bending deformation in squeeze cycle in single-sided ultrasonic welding of 2.5-mm-thick carbon-fiberreinforced nylon 6 composite resulted in severe contacts at the faying surfaces 
and likely produced significant Coulomb friction under ultrasonic oscillations, and consequently generated significant friction heat that was increased with an increase in suspension distance (i.e., distance between the clamping fixture) in single-sided ultrasonic welding.

3) The welds formed in single-sided ultrasonic welding of 2.5-mm-thick carbon-fiber-reinforced nylon 6 composite resulted from the combination of Coulomb friction heat from relative movement of the workpieces and intermolecular friction heat at the faying surfaces.

\section{Acknowledgments}

The authors gratefully acknowledge the financial and technical support provided by GM Global Research and Development to carry out the present work.

\section{References}

1. Fuchs, E. R. H., Field, F. R., Roth, R., and Kirchain, R. E. 2008. Strategic materials selection in the automobile body: Economic opportunities for polymer composite design. Composites Science and Technology 68(9): 1989-2002.

2. Strong, A. B. 1993. High Performance and Engineering Thermoplastic Composites. Lancaster, Penn.: Brent Strong Technomic Pub.Co.

3. Zah, R., Hischier, R., Leao, A. L., and Braun, I. 2007. Curaua fibers in the automobile industry - A sustainability assessment. Journal of Cleaner Production 15(11, 12): 1032-1040.

4. Duflou, J. R., De Moor, J., Verpoest, I., and Dewulf, W. 2009. Environmental impact analysis of composite use in car manufacturing. CIRP Annals - Manufacturing Technology 58(1): 9-12.

5. Orsato, R. J., and Wells, P. 2007.

U-turn: The rise and demise of the automobile industry. Journal of Cleaner Production 15(11, 12): 994-1006.

6. Vinson, J. R. 2004. Mechanical fastening of polymer composites. Polymer Engineering and Science 29(19): 1332-1339.

7. Vinson, J. R. 1989. Adhesive bonding of polymer composites. Polymer Engineering and Science 29(19): 1325-1331.

8. Strong, A. B. 1993. High Performance and Engineering Thermoplastic Composites.
Lancaster, Penn.: Brent Strong Technomic Pub. Co.

9. Todd, S. M. 1990. Joining thermoplastic composites [M]. Proceedings of the $22^{\text {nd }}$ International SAMPE Technical Conference, vol. 22, pp. 383-392.

10. Ageorges, C., Ye, L., and Hou, M. 2001. Advances in fusion bonding techniques for joining thermoplastic matrix composite: A review. Composites: Part A 32(32): 839-857.

11. Barnes, T. A., and Pashby, I. R. 2000. Joining techniques for aluminum spaceframes used in automobiles: Part II — Adhesive bonding and mechanical fasteners. Journal of Materials Processing Technology 99(1-3): 72-79.

12. Davies, P., Courty, C., Xanthopoulos, N., and Mathieu, H.-J. 1991. Surface treatments for adhesive bonding of carbon fiberpoly (etherether ketone) composites. Journal of Materials Science Letters 10(6): 335-338.

13. Grewell, D., and Benatar, A. 2007. Welding of plastics: Fundamentals and new developments. International Polymer Processing 22(1): 43-60.

14. Hou, M., Yang, M., Beehag, A., Mai, Y.-W., and Ye, L. 1999. Resistance welding of carbon fiber reinforced thermoplastic composite using alternative heating element. Composite Structures 47(1-4): 667-672.

15. Ahmed, T. J., Stavrov, D., Bersee, H. E. N., and Beukers, A. 2006. Induction welding of thermoplastic composites - An overview. Composites: Part A 37(10): 1638-1651.

16. Levy, A., Poitou, A., Le Corre, S., and Soccard, E. 2008. Ultrasonic welding of thermoplastic composites, modeling of the process. International Journal of Material Forming 1(Supplement 1): 887-890.

17. Villegas, I. F., and Bersee, H. E. N. 2010. Ultrasonic welding of advanced thermoplastic composites: An investigation on energy-directing surfaces. Advances in Polymer Technology 29(2): 112-121.

18. Levy, A., Le Corre, S., and Villegas, I. F. 2014. Modeling of the heating phenomena in ultrasonic welding of thermoplastic composites with flat energy directors. Journal of Materials Processing Technology 214(7): 1361-1371.

19. Qiu, J., Zhang, G., and Wu, Y. 2009. Proposal of ultrasonic welding technique and weld performances applied to polymers. Polymer Engineering and Science 49(9): 1755-1759.

20. Chang, J., Zheng, C., and Ni, Q.-Q. 2006. The ultrasonic wave propagation in composite material and its characteristic evaluation. Composite Structures 75(1-4):
451-456.

21. Glowska, A. W., and Pietras, A. 2012. Influence of the welding parameters on the structure and mechanical properties of vibration welded joints of dissimilar grades of nylons. Archives of Civil and Mechanical Engineering 12(2): 198-204.

22. Rani, M. R., Prakasan, K., and Rudramoorthy, R. 2005. Designing joints for ultrasonic welding of plastics. Welding Journal 84(9): 50-s to 54-s.

23. Devine, J. 2001. Ultrasonic plastic welding basics. Welding Journal 80(1): 29-s to 33-s.

24. Stokes, V. K. 2000. Assessment of geometries for determining strengths of thermoplastic vibration welds. Journal of Materials Science 35(10): 2393-2403.

25. Weihai Kaizheng Ultrasonic Technologies Co. Ltd., China.

26. Bates, P. J., MacDonald, J. J., Wang, C. Y., Mah, J., and Liang, H. 2003. Vibration welding nylon 66 - Part I: Experimental study. Journal of Thermoplastic Composite Materials 16(2): 101-119.

27. Bates, P. J., Dyck, C., and Osti, M. 2004. Vibration welding of nylon 6 to nylon 66. Polymer Engineering and Science 44(4): 760-771.

28. Sahin, O. S., Koellhoffer, S., Gillespie, J., Advani, S., and Bogetti, T. 2014. Thermal modeling during continuous ultrasonic welding. Turkish Journal of Engineering \& Sciences 38(1): 79-96.

29. Khmelev, V. N., Slivin, A. N., and Abramov, A. D. 2007. Model of process and calculation of energy for a heat generation of a welded joint at ultrasonic welding polymeric thermoplastic materials. ${ }^{\text {th }}$ Siberian Russian Workshop and Tutorial on Electron Devices and Materials.

30. Potente, H. 1984. Ultrasonic welding - Principles and theory. Materials \& Design 5(5): 228-234.

31. Chung, Y.-M., and Kamal, M. R. 2008. Morphology of PA- 6 vibration welded joints and its effect on weld strength. Polymer Engineering and Science 48(2): 240-248.

32. Elangovan, S., Semeer, S., and Prakasan, K. 2009. Temperature and stress distribution in ultrasonic metal welding An FEA-based study. Journal of Materials Processing Technology 209(3): 1143-1150.

33. Ding, Y., Kim, J., and Tong, P. 2006. Numerical analysis of ultrasonic wire bonding, effects of bonding parameters on contact pressure and frictional energy. Mechanics of Materials 38(1, 2): 11-24.

34. De Vries, E. 2004. Mechanics and Mechanism of Ultrasonic Metal Welding [M], Dissertation. The Ohio State University. 